\title{
Flexible Fuzzy Softification of Group Structures
}

\author{
V. Vanitha ${ }^{1}$, G. Subbiah ${ }^{2 *}$, M. Navaneethakrishnan ${ }^{3}$ \\ ${ }^{1}$ Department of Mathematics, Kamaraj College, Thoothukudi-628 003, Tamil Nadu, India \\ ${ }^{2}$ Department of Mathematics, Sri K. G. S. Arts College, Srivaikuntam-628 619,Tamil Nadu, India \\ ${ }^{3}$ Department of Mathematics, Kamaraj College, Thoothukudi-628 003,Tamil Nadu, India \\ (Affiliated to Manonmaniam Sundaranar University, Abishekapatti, Tirunelveli,India) \\ *Corresponding Author: subbiahkgs@gmail.com
}

Available online at: www.isroset.org

Accepted 13/Aug/2018, Online 30/Aug/2018

Abstract: In this paper, we introduce the concept of upper t-subgroups of a flexible fuzzy soft intersection group (FFSIG) and investigate various structures of flexible fuzzy soft intersection groups related to upper t- subgroups with suitable example.

Keywords: soft set, fuzzy soft set, soft int-group, upper t-subgroup, flexible fuzzy set, inclusion, relative complement.

\section{INTRODUCTION}

The algebraic structures of soft set theory have also been studied extensively. Aktas and Cagman [2] introduced the basic concepts of soft groups, soft subgroups, normal soft subgroups and soft homomorphism and discussed their basic properties. Feng et.al $[5,6]$ considered the algebraic structure of semi ring and introduced the notion of soft semi ring. Some basic algebraic properties of soft semi ring and some related notions such as soft ideals, idealistic soft semi rings and soft semi ring homomorphism were defined and investigated with illustrative examples .Jun [8] applied the notion of soft sets to the theory of BCK/BCI- algebras and introduced the notion of soft BCK/ BCI- algebras, soft sub algebras and then derived their basic properties.Jun and Park [9] introduced the concept of soft Hilbert algebra, soft Hilbert abysmal algebra, soft Hilbert deductive algebra and investigated their properties. Jun [7] also in another paper, introduced the notion of soft p- ideals , p- idealistic soft BCI- algebras and discussed their basic properties. Based on the work of [5,6], introduced the basic notions of soft rings as a parameterized family of subrings of a ring over a ring with some illustrative examples. The notions of soft subrings, soft ideal of a soft ring, idealistic soft rings and soft ring homomorphism were introduced with some corresponding example. They made a theoretical study of the algebraic structures of soft sets such as lattice structures and introduced the concept of soft equality relation and also discussed its related properties. It was proved that soft equality relation is a congruence relation with respect to some operations. In relation to the work of [1] , introduced some new operations on soft ring such as extended sum, restricted sum, extended product, restricted product and established some of their basic properties. Ali et.al[3] defined some algebraic structures such as semi groups, semi rings and lattices associated with soft sets and completely described the distributive and absorption laws on operations of soft sets. MV-algebras and BCK-algebras associated with soft set, with a fixed set of parameters were also studied. Atagun and Sezgin $[15,16]$ introduced and studied some sub-structures such as soft subrings and soft ideals of a ring, soft subfield of a field and soft sub module of a module with several illustrative examples. Some related properties on operations of restricted intersection, product and sum for these soft sub- structures were established and investigated with examples. By introducing the concept of normalistic soft group, normalistic soft group homomorphism and establishing that the normalistic soft group isomorphism is an equivalence relation on normalistic soft groups which defined in [2]. Jun et.al [9] discussed the notion of positive implicative ideals of BCK-algebras based on soft set theory and their basic properties. On flexible fuzzy subgroups with flexible fuzzy order discussed by [17] .In this paper, we introduce the concept of upper t-subgroups of a flexible fuzzy soft intersection group (FFSIG) and analyse various structures of flexible fuzzy soft intersection groups related some softification of upper t-subgroups.

\section{PRELIMINARIES}

Definition 2.1[Molodtsov]: A pair $(F, A)$ is called a soft set over $U$, where $F$ is a mapping given by $F: A \rightarrow P(U)$.In other words, a soft set over $U$ is a parameterized family of subsets of the universe U.Note that a soft set $(F, A)$ can be denoted by $F_{A}$. 
In this case, when we define more than one soft set in some subsets $\mathrm{A}, \mathrm{B}, \mathrm{C}$ of parameters $\mathrm{E}$, the soft sets will be denoted by $\mathrm{F}_{\mathrm{A}}, \mathrm{F}_{\mathrm{B}}, \mathrm{F}_{\mathrm{C}}$ respectively. On the other case, when we define more than one soft set in a subset $\mathrm{A}$ of the set of parameters $\mathrm{E}$, the soft sets will be denoted by $\mathrm{F}_{\mathrm{A}}, \mathrm{G}_{\mathrm{A}}, \mathrm{H}_{\mathrm{A}}$ respectively.

Definition 2.2[Molodtsov]:The relative complement of the soft set $F_{A}$ over $U$ is denoted by $F_{A}^{r}$, where $F_{A}^{r}: A \rightarrow P(U)$ is a mapping given as $\mathrm{F}_{\mathrm{A}}^{\mathrm{r}}(\mathrm{a})=\mathrm{U} \backslash \mathrm{F}_{\mathrm{A}}(\mathrm{a})$, for all $\mathrm{a} \in \mathrm{A}$.

Definition2.3[Molodtsov]: Let $F_{A}$ and $G_{B}$ be two soft sets over $U$ such that $A \cap B \neq \emptyset$, The restricted intersection of $F_{A}$ and $G_{B}$ is denoted by $F_{A} \in G_{B}$, and is defined as $F_{A} \in G_{B}=(H, C)$, where $C=A \cap B$ and for all $c \in C, H(c)=F(c) \cap G(c)$.

Definition 2.4[Molodtsov] : Let $F_{A}$ and $G_{B}$ be two soft sets over $U$ such that $A \cap B \neq \emptyset$. The restricted union of $F_{A}$ and $G_{B}$ is denoted by $F_{A} \cup_{R} G_{B}$, and is defined as $F_{A} \cup_{R} G_{B}=(H, C)$, where $C=A \cap B$ and for all $c \in C, H(c)=F(c) \cup G(c)$.

Definition 2.5[Zadeh]: A function ' $\mathrm{f}$ ' is defined from a universe $\mathrm{X}$ to a closed interval $[0,1]$ is called a fuzzy set (i,e) a mapping $\quad \mathrm{f}: \mathrm{X} \rightarrow[0,1]$.

Definition2.6: Let $\mathrm{F}_{\mathrm{A}}$ be a soft set over $\mathrm{U}$ and $\mathrm{Abe}$ a subset of $\mathrm{U}$. Then upper $\alpha$-inclusion of $\mathrm{F}_{\mathrm{A}}$, denoted by $F_{\bar{A}}^{\supset \alpha}$, is defined as $F_{A}^{\supseteq \alpha}=\{\mathrm{x} \in \mathrm{A} / \mathrm{F}(\mathrm{x}) \supseteq \alpha\}$. Similarly,

$F_{A}^{\subseteq \alpha}=\{\mathrm{x} \in \mathrm{A} \mid \mathrm{F}(\mathrm{x}) \subseteq \alpha\}$ is called the lower $\alpha$-inclusion of $\mathrm{F}_{\mathrm{A}}$.

Definition2.7 [Naim Cagman]:Let $U$ be an initial universe, $E$ be the set of all parameters and $A \subseteq E$. A pair (F, A) is called a flexible fuzzy soft set over $\mathrm{U}$ where $\mathrm{F}: \mathrm{A} \rightarrow \tilde{P}(\mathrm{U})$ is a mapping from A into $\widetilde{P}(\mathrm{U})$, where $\tilde{P}(\mathrm{U})$ denotes the collection of all subsets of U.

Definition 2.8: Let $\mathrm{G}$ be a group and $\delta$ be a flexible fuzzy soft over $\mathrm{X}$. If for all $\mathrm{x}, \mathrm{y} \in \mathrm{G}$

(i) $\max \{\delta(\mathrm{xy})\} \leq \min \{\delta(\mathrm{x}) \cap \delta(\mathrm{y})\}$ and

(ii) $\max \left\{\delta\left(\mathrm{x}^{-1}\right)\right\} \leq \min \{\delta(\mathrm{x})\}$, then the flexible fuzzy soft set $\delta$ is called a flexible fuzzy soft int-subgroup of $\mathrm{X}$ and denoted by $\delta \subsetneq \mathrm{G}$.

Example 2.9: Let $G=Z_{4}$ be the set of parameters and $U=\{1,-1, i,-i\}$ be the universal set of a flexible fuzzy soft set over $U$ is constructed by

$\delta_{\mathrm{G}}(0)=\{1,-1, \mathrm{i},-\mathrm{i}\}$

$\delta_{\mathrm{G}}(1)=\delta_{\mathrm{G}}(3)=\{\mathrm{i}\}$

$\delta_{\mathrm{G}}(2)=\{1, \mathrm{i}\}$. Clearly $\delta_{\mathrm{G}}$ is flexible fuzzy soft intersection group over U. Here

$\operatorname{Im}\left(\delta_{\mathrm{G}}\right)=\{\{\mathrm{i}\},\{1, \mathrm{i}\},\{1 .-1, \mathrm{i},-\mathrm{i}\}\}$, thus all the upper t-sub groups of $\delta_{\mathrm{G}}$ are $\delta_{\mathrm{G}} \supseteq\{i\}=\mathrm{Z}_{4,} \quad \delta_{\mathrm{G}} \supseteq\{1, i\}=\{0,2\}, \quad \delta_{\mathrm{G}} \supseteq\{1,-1, i,-i\}=$ $\{0\}$.

Now, let define a flexible fuzzy soft set over U such that

$\Delta_{G}\{0\}=\{1,-1, \mathrm{i}\}, \Delta_{G}\{1\}=\mathrm{h}_{\mathrm{G}}(3)=\{-1\}, \Delta_{G}\{2\}=\{-1, \mathrm{i}\}$.

Obviously, $\Delta_{G}$ is a FFSI - group over U. Too and the family of upper $\mathrm{t}-$ subgroups of $\Delta_{G}$ are $\Delta_{G} \supseteq\{-1\}=\mathrm{Z}_{4}, \Delta_{G} \supseteq\{-1, i\}=\{$ $0,2\}$

$\Delta_{G} \supseteq\{1,-1, i\}=\{0\}$. It is seen that two FFSI - groups $\delta_{G}$ and $\mathrm{h}_{\mathrm{G}}$ have the same family of upper t-subgroups, however $\delta_{\mathrm{G}}$ is not soft equal to $\Delta_{G}$.

\section{PROPERTIES OF FLEXIBLE FUZZY SOFT INTERSECTION GROUPS}

Proposition 3.1: Let $\mathrm{S}_{\mathbf{G}}$ be the class of FFSI - groups of a group G over U. If define a relation R on $\mathrm{S}_{\mathbf{G}}$ by $\delta_{\mathrm{G}} \mathrm{R} \Delta_{G}$, then its upper $\mathrm{t}$-subgroups on the relation $\mathrm{R}$ is an equivalence relation.

Note 3.2: Example 2.9, it is shown that $\Delta_{G}$ and $\delta_{\mathrm{G}}$ may be such that $\delta_{\mathrm{G}} \mathrm{R} \Delta_{G}$ but $\delta_{\mathrm{G}}$ and $\Delta_{G}$ need not be soft equal. The equivalence relation defined in this proposition $3.1 \mathrm{~S}_{\mathrm{G}}$ into equivalence classes.

Let $\delta_{\mathrm{G}} \in \mathrm{S}_{\mathrm{G}}$ and $\left|\delta_{\mathrm{G}}\right|$ denote the equivalence class contained $\delta_{\mathrm{G}}$. If the group $\mathrm{G}$ is finite, then the number of possible distinct upper t-subgroups are finite, as each upper t-subgroups is a subgroup of $\mathrm{G}$ in the usual sense. All these remarks lead us 
to the conclusion that the number of possible chains of upper t-subgroups, we have the following that the number of equivalence is finite, although $S_{G}$ is an infinite family when $U$ is infinite.

Corollary 3.3: If $G$ is a finite group, then the number of distinct equivalence classes in $S_{G}$ under the definition of equivalence relation defined in proposition 3.1 is finite.

Moreover, $\mathrm{S}_{\mathrm{G}}$ can be written as a disjoint Union

$\mathrm{S}_{\mathrm{G}}=\left|\delta_{\mathrm{G}}{ }^{1} \mathrm{U}\right| \delta_{\mathrm{G}}{ }^{2}|\mathrm{U}| \delta_{\mathrm{G}}{ }^{3}|\mathrm{U} \ldots \ldots \ldots . . \mathrm{U}| \delta_{\mathrm{G}}{ }^{\mathrm{k}} \mid$ where $\left|\delta_{\mathrm{G}}{ }^{\mathrm{i}}\right|$ denotes $1 \leq \mathrm{i} \leq \mathrm{k}$ on all distinct equivalence classes. Here, again note that $\mid$ $\delta_{\mathrm{G}}{ }^{\mathrm{i}} \mid$ has an infinite number of FFSI - groups when $\mathrm{U}$ is finite.

Proposition 3.4: Let $\Delta_{G}$ and $\delta_{\mathrm{G}}$ be two FFSI- groups of a finite group G having the identical family of upper t-subgroups and the sets $\operatorname{Im}\left(\delta_{\mathrm{G}}\right)$ and $\operatorname{Im}\left(\Delta_{G}\right)$ be ordered by combination.

If $\operatorname{Im}\left(\delta_{\mathrm{G}}\right)=\left\{\mathrm{t}_{\mathbf{0}}, \mathrm{t}_{\mathbf{1}}, \mathrm{t}_{2}, \ldots . ., \mathrm{t}_{\mathbf{m}}\right\}$ and $\operatorname{Im}\left(\Delta_{G}\right)=\left\{\mathrm{s}_{\mathbf{0}}, \mathrm{s}_{\mathbf{1}}, \ldots ., \mathrm{s}_{\mathbf{n}}\right\}$, then

(ii) $\quad \delta_{\mathrm{G}} \supseteq \mathfrak{t i}^{\prime}=\delta_{\mathrm{G}} \supseteq \supseteq^{s i}, 0 \leq \mathrm{i} \leq \mathrm{m}$,

(iii) If $\mathrm{x} \in \mathrm{G}$ such that $\delta_{\mathrm{G}}(\mathrm{x})=\mathrm{t}_{\mathrm{i}}$, then $\Delta_{G}(\mathrm{x})=\mathrm{s}_{\mathrm{i}}, 0 \leq \mathrm{i} \leq \mathrm{m}$.

Proof: (i) Since $\Delta_{G}$ and $\delta_{\mathrm{G}}$ have the identical family of upper $\mathrm{t}$-subgroups, it follows that $\mathrm{m}=\mathrm{n}$.

(ii) Since $t_{0} \geq t_{1} \geq t_{2} \geq \ldots . . \geq t_{m}$ and $s_{0} \geq s_{1} \geq s_{2} \geq \ldots \ldots \geq s_{n}$, by proposition 3.1 that two chains of upper $t-$ subgroups are $\delta_{\mathrm{G}}{ }^{\supseteq t_{o}} \leq \delta_{\mathrm{G}} \beth^{t}{ }_{1 \leq \delta_{\mathrm{G}}}{ }^{t}{ }_{2} \leq \ldots \ldots \ldots . . . \delta_{\mathrm{G}}{ }^{t}{ }_{n}=\mathrm{G}$,

$\left.\Delta_{G}\right\urcorner^{t_{o}} \leq \Delta_{G}{ }^{t}{ }_{1} \leq \Delta_{G}{ }^{t}{ }_{2} \leq \ldots \ldots \ldots . . . \Delta_{G}{ }^{t}{ }_{n}=\mathrm{G}$.

Since the two upper t- subgroups are identical, it is obvious that

$\delta_{\mathrm{G}} \supseteq^{t_{o}}=\Delta_{G} \stackrel{t}{o}^{\prime}=\{\mathrm{e}\}$.

Let $\delta_{\mathrm{G}}{ }^{t}{ }_{1}=\Delta_{G}{ }^{t}{ }_{1}$, for some $\mathrm{j}>0$.

Suppose that $\delta_{\mathrm{G}} \supseteq{ }_{j}=\Delta_{G} \supseteq{ }_{j}$ for some $\mathrm{j}>1$.

Again $\Delta_{G} \supseteq{ }^{s} i=\Delta_{G} \supseteq{ }^{t} i$ for some $\mathrm{t}_{\mathbf{1}} \geq \mathrm{t}_{\mathbf{i}}$.

It is obvious that $\mathrm{t}_{\mathbf{i}} \neq \mathrm{t}_{1}$. Thus $\delta_{\mathrm{G}} \supseteq{ }^{t} i=\Delta_{G} \supseteq s i \subset \Delta_{G} \supseteq{ }_{j}$, so $\delta_{\mathrm{G}} \supseteq{ }^{t} i=\Delta_{G} \supseteq{ }_{j}$.

Now $\Delta_{G} \supseteq{ }_{j}{ }_{j} \delta_{\mathrm{G}} \supseteq^{t} i \subset \delta_{\mathrm{G}} \supseteq^{t} i$, so $\Delta_{G} \supseteq{ }_{j} \subset \delta_{\mathrm{G}} \supseteq^{t} i$

Note that, $\delta_{\mathrm{G}}{ }^{t} i \subset \delta_{\mathrm{G}}{ }^{t} i$

Contradicts one another, because the combination are both proper combination, so $\delta_{\mathrm{G}}{ }^{t} i \subset \Delta_{G}{ }^{\supseteq} i$. The rest of the proof follows by induction method on i. Finally, it is obtained that $\delta_{\mathrm{G}}{ }^{2 t} i=\Delta_{G} \supseteq{ }_{j}, 0 \leq \mathrm{i} \leq \mathrm{m}$.

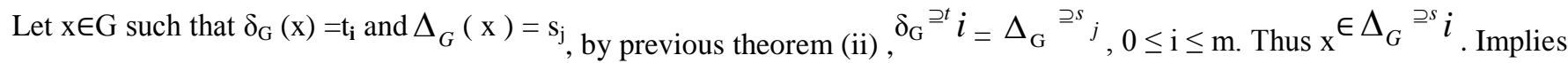
that

$\Delta_{G}(\mathrm{x})=\mathrm{s}_{\mathrm{j}}$ such that $\mathrm{s}_{\mathrm{j}} \geq \mathrm{s}_{\mathrm{i}}$. So $\Delta_{G} \stackrel{s}{s}_{j} \leq \Delta_{G}{ }^{s} i$.

Similarly, by previous theorem (ii) $\Delta_{G} \supseteq{ }_{j}{ }_{j}=\Delta_{G} \supseteq{ }^{s} i$.

Therefore, since $\mathrm{x} \in \Delta_{G} \supseteq{ }^{s} i, \mathrm{x} \in \delta_{G} \supseteq{ }^{s} j$ and so,

$\delta_{\mathrm{G}}(\mathrm{x})=\mathrm{t}_{\mathrm{i}} \geq \mathrm{t}$.

It follows that $\left.\delta_{\mathrm{G}}\right\urcorner^{t} i_{\leq} \delta_{\mathrm{G}} \supseteq^{t} j$

However, by theorem (ii),,$_{\mathrm{G}}^{\supseteq t} i=\Delta_{G}{ }^{s} i$ and $\delta_{\mathrm{G}} \supseteq{ }^{t} j=\Delta_{G} \supseteq{ }_{j}$. So,

$\left.\Delta_{G} \supseteq^{s} i=\delta_{\mathrm{G}}{ }^{t} i \subset \delta_{\mathrm{G}}\right\urcorner^{t} j=\Delta_{G} \supseteq^{s} j$,

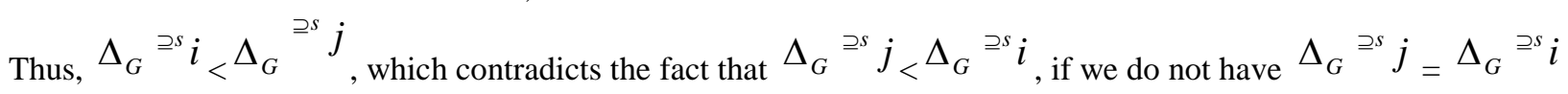




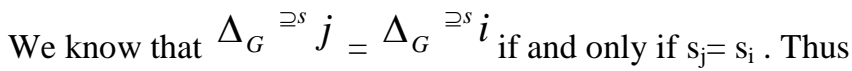

$\delta_{\mathrm{G}}(\mathrm{x})=\mathrm{t}_{\mathrm{i}}$, and $\Delta_{G}(\mathrm{x})=\mathrm{s}_{\mathrm{j}}=$ si. Hence the proof.

Proposition 3.5:Let ${ }_{G_{G}}$ and ${ }^{\Delta} G$ be two FFSI - groups of a finite group G such that their family of upper $\mathrm{t}$ - subgroups are identical and their image sets are both ordered by combination. Thus $\delta_{\mathrm{G}}=\Delta_{G}$, then $\operatorname{Im}\left(\delta_{\mathrm{G}}\right)=\operatorname{Im}\left(\Delta_{G}\right)$.

Proof: $\operatorname{Let} \delta_{\mathrm{G}}={ }^{\Delta_{G}}$. Then $\operatorname{Im}\left(\delta_{\mathrm{G}}\right)=\operatorname{Im}\left(\Delta_{G}\right)$ is obvious.

Conversely, suppose that $\operatorname{Im}\left(\delta_{\mathrm{G}}\right)=\operatorname{Im}\left(\Delta_{G}\right) \cdot \operatorname{Let} \operatorname{Im}\left(\delta_{\mathrm{G}}\right)=\left\{\mathrm{t}_{\mathbf{0}}, \mathrm{t}_{\mathbf{1}}, \mathrm{t}_{\mathbf{2}}, \ldots \ldots, \mathrm{t}_{\mathbf{n}}\right\}$ and

$\operatorname{Im}\left(\Delta_{G}\right)=\left\{\mathrm{s}_{\mathbf{0}}, \mathrm{s}_{\mathbf{1}}, \mathrm{s}_{\mathbf{2}}, \ldots \ldots, \mathrm{s}_{\mathbf{n}}\right\}$ such that $\mathrm{t}_{\mathbf{0}} \geq \mathrm{t}_{\mathbf{1}} \geq \ldots \ldots . \mathrm{t}_{\mathbf{n}}$ and $\mathrm{s}_{\mathbf{0}} \geq \mathrm{s}_{\mathbf{1}} \geq \mathrm{s}_{2} \ldots . . \mathrm{s}_{\mathbf{n}}$.

Let $\mathrm{s}_{\mathrm{o}} \in \operatorname{Im}\left(\delta_{\mathrm{G}}\right)$.Thus $\mathrm{s}_{\mathrm{o}}=\mathrm{t}_{\alpha 0}$ for some $\alpha_{\mathrm{o}}$.

Let $\mathrm{t}_{\alpha \mathrm{o}} \neq \mathrm{t}_{\mathrm{o}}$. It follows that $\mathrm{t}_{\alpha \mathrm{o}} \nsupseteq \mathrm{t}_{\mathrm{o}}$.

Since $t_{0}$ is the maximal element of the chain.

Now, let $\mathrm{s}_{\mathbf{1}} \in \operatorname{Im}\left(\delta_{\mathrm{G}}\right)$ and $\mathrm{s}_{\mathrm{o}} \mathrm{s}_{\mathbf{1}}=\mathrm{t}_{\boldsymbol{\alpha} 1 \mathrm{1}}$ for some $\mathrm{t}_{\mathbf{1}}$.

Since $S_{o} \nsupseteq S_{1}$, it implies that ${ }^{t} \alpha_{o} \supset t_{a 1}$. Similarly,

$\mathrm{t} \alpha_{\mathrm{o}} \supset \mathrm{t} \alpha_{1} \supset \mathrm{t} \alpha_{2} \supset \ldots \ldots \ldots . . . \supset \mathrm{t}_{\mathrm{r}}$, where $\mathrm{s}_{0}=\mathrm{t}_{\mathrm{o}} \nsupseteq \mathrm{t}_{\mathrm{o}}$.

This means that there does not exist only $\mathrm{s}_{\mathrm{i}} \in \operatorname{Im}\left(\Delta_{G}\right)$ such that $\mathrm{t}_{\mathrm{o}}=\mathrm{s}_{\mathrm{i}}$.

But the contradicts the fact that $\operatorname{Im}\left(\delta_{\mathrm{G}}\right)=\operatorname{Im}\left(\Delta_{G}\right)$

Hence we must have $s_{0}=t_{0}$.

Similarly, one can obtain that $\mathrm{s}_{\mathrm{i}}=\mathrm{t}_{\mathrm{i}}, 0 \leq \mathrm{i} \leq \mathrm{r}$.

By proposition 3.4 (iii), $\Delta_{G}\left(\mathrm{l}_{\mathrm{i}}\right)$, for all $\mathrm{i} \in \mathrm{G}$. Hence $\delta_{\mathrm{G}}=\Delta_{G}$.

Hence the proof.

Note3.6: Since all the subgroups of G, in general, do not form a chain. We can conclude that not all subgroups of $G$ are upper t-subgroups of a given FFSI-group whose image set form a chain. Therefore, it turns out to be an interesting problem to find FFSI-group whose image sets form a chain and which accommodates as many subgroups of $\mathrm{G}$ as possible in the chain of upper t- subgroups of the FFSI group.

Theorem 3.7 : Any subgroup H of a group G can be realized as an upper t- subgroups of some FFSI - group over U.

Proof: Let $\delta_{\mathrm{G}}$ be a FFSI - set over U defined by

$\delta_{\mathrm{G}}(\mathrm{x})=\left\{\begin{array}{l}\mathrm{t}, \text { if } \mathrm{x} \in \mathrm{H} \\ \Phi, \text { if } \mathrm{x} \notin \mathrm{H} . \text { Then } \delta_{\mathrm{G}} \text { is a FFSI - group over } \mathrm{U} .\end{array}\right.$

Let $a, b \in G$.

Case (i) : Suppose $\mathrm{a} \in \mathrm{H}$ and $\mathrm{b} \in \mathrm{H}$, then $\mathrm{ab} \in \mathrm{H}$.

It follows that $\max \left\{\delta_{\mathrm{G}}(\mathrm{ab})\right\}=\mathrm{t}$ and $\delta_{\mathrm{G}}(\mathrm{a})=\delta_{\mathrm{G}}(\mathrm{b})=\mathrm{t}$.

Thus, $\max \left\{\delta_{\mathrm{G}}(\mathrm{ab})\right\} \leq \min \left\{\delta_{\mathrm{G}}(\mathrm{a}), \delta_{\mathrm{G}}(\mathrm{b})\right\}$.

And also if $\in_{\mathrm{a}} \mathrm{H}$, then so is $\mathbf{a}^{-1}$, thus $\delta_{\mathrm{G}}(\mathrm{a})=\delta_{\mathrm{G}}\left(\mathrm{a}^{-\mathbf{1}}\right)=\mathrm{t}$.

Case (ii) : Now, suppose $\mathrm{a} \in \mathrm{H}$ and $\mathrm{b} \notin \mathrm{H}$ then $\mathrm{ab} \notin \mathrm{H}$. It follows that

$\delta_{\mathrm{G}}(\mathrm{a})=\mathrm{t}$ and $\delta_{\mathrm{G}}(\mathrm{b})=\delta_{\mathrm{G}}(\mathrm{ab})=\Phi$.

Therefore, $\max \left\{\delta_{\mathrm{G}}(\mathrm{ab})\right\} \geq \min \left\{\delta_{\mathrm{G}}(\mathrm{a}), \delta_{\mathrm{G}}(\mathrm{b})\right\}$.

Furthermore $\delta_{\mathrm{G}}(\mathrm{a})=\delta_{\mathrm{G}}\left(\mathrm{a}^{-1}\right)$ if a $\in_{\mathrm{H}}$ or a $\notin \mathrm{H}$.

Case (iii) : Now, suppose that $\mathrm{a} \notin_{\mathrm{H}}$ and $\mathrm{b} \notin \mathrm{H}$. Then either $\mathrm{a}, \mathrm{b} \in \mathrm{H}$ or a,b $\mathrm{b}^{\notin} \mathrm{H}$. It is easy to show that in any cases, $\max \left\{\delta_{\mathrm{G}}(\right.$ $\mathrm{ab})\} \leq \min \left\{\delta_{\mathrm{G}}(\mathrm{a}), \delta_{\mathrm{G}}(\mathrm{b})\right\}$.

And $\delta_{\mathrm{G}}(\mathrm{a})=\delta_{\mathrm{G}}\left(\mathrm{a}^{-1}\right)$. 
Hence $\delta_{\mathrm{G}}$ is a FFSI - group over U.Therefore, for this FFSI group, $\delta_{\mathrm{G}} \stackrel{t}{t}=\mathrm{H}$.

Note 3.8: It is known that if $\delta_{G}$ is a FFSI group over $U$, then $\delta_{G}(e) \geq \delta_{G}(x)$ for all $x \in_{G}$.

Let $\delta_{\mathrm{G}}(\mathrm{e}) \geq \mathrm{t}_{\mathrm{e}}$. Then it turns out to be an interesting case to investigate the upper t $\mathrm{e}_{\mathrm{e} u b g r o u p ~ o f} \delta_{\mathrm{G}}{ }^{\supseteq} e_{\mathrm{of}} \mathrm{G}$. Because it $\mathrm{x} \in \delta_{\mathrm{G}}$ ${ }^{\supseteq} e$, then $\delta_{\mathrm{G}}(\mathrm{x}) \geq \mathrm{t}=\delta_{\mathrm{G}}$ ( e ) and it appears that only e $\in \delta_{\mathrm{G}}{ }^{t} e$. But that is not always the case as seen in the following example.

Example 3.9: Consider the FFSI - group in theorem 3.7. Assume that $\mathrm{H} \neq\{$ e $\}$ and $\mathrm{H} \neq \mathrm{G}$. It is known that $\delta_{\mathrm{G}}$ is a FFSI group over $\mathrm{U}$ and $\operatorname{Im}\left(\delta_{\mathrm{G}}\right)=\{\Phi, \mathrm{t}\}$.

Thus, two upper $\mathrm{t}$ - subgroups are $\delta_{\mathrm{G}} \supseteq \phi=\mathrm{G}$ and $\delta_{\mathrm{G}} \supseteq{ }^{t}=\left\{\mathrm{x} \in \mathrm{G} / \delta_{\mathrm{G}}(\mathrm{x}) \geq \mathrm{t}\right\}=\mathrm{H}$.

Since $\mathrm{e} \in \mathrm{H}, \delta_{\mathrm{G}}(\mathrm{e})=\mathrm{t}$; but $\delta_{\mathrm{G}} \supseteq{ }^{t}=\mathrm{H}$, which is not equal to "e".

Definition 3.10: Let $\delta_{\mathrm{G}}$ be a FFSI - group over $\mathrm{U}$. Then e-set of $\delta_{\mathrm{G}}$, denoted by $\mathrm{G}_{\boldsymbol{\delta} \mathrm{G}}$, is defined as $\mathrm{G}_{\boldsymbol{\delta}}=\left\{\mathrm{x} \in \mathrm{G} / \delta_{\mathrm{G}}(\mathrm{x})=\delta_{\mathrm{G}}(\mathrm{e})\right.$ \}

Theorem 3.11: Let $\delta_{\mathrm{G}}$ be a FFSI - group over U. If $\delta_{\mathrm{G}}^{(\mathrm{e})}=\mathrm{t}_{\mathbf{e}}$, then $\delta_{\mathrm{G}}{ }^{t}{ }_{\mathrm{e}}=\mathrm{G}_{\delta \mathrm{G}}$.

Proof: $\delta_{\mathrm{G}}{ }_{\mathrm{e}}^{t} \quad=\left\{\mathrm{x} \in \mathrm{G} / \delta_{\mathrm{G}}{ }^{(\mathrm{x})} \geq \mathrm{t}_{\mathrm{e}}\right\}$

$$
=\left\{\mathrm{x} \in \mathrm{G} / \delta_{\mathrm{G}}{ }^{(\mathrm{x})}=\mathrm{t}_{\mathrm{e}}\right\}
$$

Since $\mathrm{t}_{\mathrm{e}} \geq \delta_{\mathrm{G}}{ }^{(\mathrm{x})}$ for all $\mathrm{x} \in \mathrm{G}$.

$\delta_{\mathrm{G}}{ }^{t}{ }_{\mathrm{e}}=\left\{\mathrm{x} \in \mathrm{G} / \delta_{\mathrm{G}}^{(\mathrm{x})}=\delta_{\mathrm{G}}^{(\mathrm{e})}\right\}=\mathrm{G}_{\delta \mathrm{G}}$.

Note 3.12: Let $\delta_{G}$ be a FFSI - group over $U$ and $\left(t_{0}, t_{1}, t_{2}, t_{3}, \ldots \ldots, t_{n}\right\} \in \operatorname{Im}\left(\delta_{G}\right)$ which satisfying that $t_{0} \geq t_{1} \geq t_{2} \geq t_{3} \geq \ldots \ldots \geq t_{n}$. Then the family of upper $-\mathrm{t}$ - subgroups from a chain, which denoted by $\mathrm{C}\left(\delta_{\mathrm{G}}\right)=\delta_{\mathrm{G}}{ }^{t}{ }_{0<\delta_{\mathrm{G}}}{ }^{t}{ }_{1<\ldots \ldots . .}{ }^{<\delta_{\mathrm{G}}}{ }^{t} \mathrm{n}$.

Not to our surprise, only some of the upper t-subgroups of $\delta_{\mathrm{G}}$ form a chain. Since all the subgroups of $\mathrm{G}$, but in general, does not form a chain that is, it makes no sense to hope all the upper $\mathrm{t}$ - subgroups form a chain.

In the connection, see example 2.9, $\{0,3\} \not \subset\{0,2,4\}$ and $\{0,2,4\} \not \subset(0,3\}$.

Of course if the number of the $\operatorname{Im}\left(\delta_{\mathrm{G}}\right)$ forms a chain, so does the upper $\mathrm{t}-$ subgroups of $\delta_{\mathrm{G}}$. For further detail, refer to the following theorem.

Theorem 3.13: Let $\mathrm{G}$ be a finite group.Let $\delta_{\mathrm{G}}$ be a FFSI - group over $\mathrm{U}, \mathrm{I}$ be an arbitrary finite index set and G $\left(\delta_{\mathrm{G}}{ }^{t}\right)=\left\{\delta_{\mathrm{G}}\right.$ $\left.\supseteq^{t}{ }_{\mathrm{i}} / \mathrm{i} \in \mathrm{I}, \mathrm{t}_{\mathrm{i}} \in \operatorname{Im}\left(\delta_{\mathrm{G}}\right)\right\}$, then we have the followings:

(i) There exists a unique $\mathrm{i}_{\mathbf{e}} \in \mathrm{I}$ such that $\mathrm{t}_{\mathbf{i}} \geq \mathrm{t}_{\mathbf{i}}$, for all $\mathrm{i}$.

(ii) $\quad \mathrm{G}_{\delta \mathrm{G}}=\bigcap_{i \in I} \delta_{\mathrm{G}}{ }^{\mathrm{ti}}=\delta_{G} \supseteq t_{i e}$

$\mathrm{G}=\bigcup_{i \in I} \delta_{G} \supseteq{ }^{t i}$

(iv) If the members of $\operatorname{Im}\left(\delta_{\mathrm{G}}\right)$ forms a chain, so do is $\mathrm{G}\left(\delta_{\mathrm{G}} \supseteq t i\right)$.

\section{Proof:}

(i) $\quad$ Since $\delta_{G}^{(e)} \in \operatorname{Im}(\delta G)$, there exists a unique $i_{e} \in$ I such that $\delta_{G}(e)=t i e$.

We know that $\delta_{G}{ }^{(\mathrm{e})} \geq \delta_{\mathrm{G}}{ }^{(\mathrm{x})}$ for all $\mathrm{x} \in \mathrm{G}$.

It follows that $t_{i e} \geq \delta_{G}{ }^{(x)}$, for all $x \in G$.

Thus $\mathrm{t}_{\mathrm{ie}} \geq \mathrm{t}_{\mathrm{i}}$, for all $\mathrm{i} \in \mathrm{I}$.

(ii) Since in theorem 3.12 , it is proved that

$\mathrm{G}_{\delta \mathrm{G}}=\delta_{G} \supseteq t_{i e}$, where $\delta_{\mathrm{G}}^{(\mathrm{e})}=\mathrm{t}_{\text {ie }}$.

It is only shows that $\mathrm{G} \delta_{G} \supseteq t_{i e}=\bigcap_{i \in I} \delta_{\mathrm{G}}{ }^{\mathrm{ti}} \quad$. Since $\mathrm{t}_{\mathbf{i e}} \geq \mathrm{t}_{\mathbf{i}}$ for all $\mathrm{i} \in \mathrm{I}$, 


$$
\begin{aligned}
& \mathrm{G}_{\boldsymbol{\delta} \mathbf{G}} \stackrel{\supseteq t_{i e}}{\leq} \mathrm{G}_{\delta \mathbf{G}} \stackrel{\supseteq t_{i e}}{ } \text {, for all } \mathrm{i} .
\end{aligned}
$$

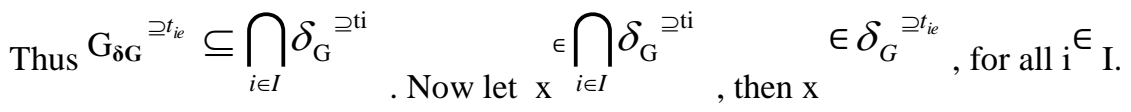

\section{CONCLUSION}

we conclude that not all subgroups of $G$ are upper t-subgroups of a given FFSI-group whose image set form a chain. Therefore, it turns out to be an interesting problem to find FFSI-group whose image sets form a chain and which accommodates as many subgroups of $\mathrm{G}$ as possible in the chain of upper t- subgroups of the FFSI group.In this connection ,any subgroup $\mathrm{H}$ of a subgroup $\mathrm{G}$ can be realized as an upper -subgroups of some FFSI-group over U.

\section{FUTURE WORK}

To extend our work, further research can be done to study the properties of multi- fuzzy soft int-group in other algebraic structures such as modules, rings and fields.

\section{ACKNOWLEDGEMENT}

The authors are highly grateful to the referees for their valuable comments and suggestions for improving the paper.

\section{REFERENCES}

[1]. AcarU, Koyuncu F, and Tanay B, (2010), Soft sets and soft rings. Computers and Mathematics with Applications, 59: 3458 - 3463.

[2]. Aktas H and Cagman N, (2007), Soft sets and soft groups, Information Sciences, 1: 2726-2735.

[3]. Ali M. I, Feng F, Lui X, Min W. K and Shabir M, (2009), On some new operations in soft set theory, Computers and Mathematics with Applications, 57: 1547- 1553.

[4]. Atagun A. O and Sezgin A, (2011), Soft substructures of rings, fields and modules. Computers and Mathematics with Applications, 61: 592601.

[5]. Feng F, Jun Y. B and Zhao X, (2008), Soft semirings. Computers and Mathematics with Applications, 56: 2621 - 2628.

[6]. Feng F and Li Y, (2013), Soft subsets and Soft product operations. Information Science, 232:44-57.

[7]. Jun Y.B, (2008), Soft BCK/BCI-algebras, Computers and Mathematics with Applications, 56: 1408-1413.

[8]. Jun Y.B and Park C.H, (2008), Applications of soft sets in ideals theory of BCK/BCI- algebras, Information Sciences, 178: $2466-2475$.

[9]. Jun Y.B , Kim H.S and Park C.H, (2011), Positive implicative ideals of BCKalgebras based on a soft set theory, Bulletin of the Malaysian Mathematical Science, Society, 34(2): 345-354.

[10]. Maji P. K, Biswas R, and Roy A. R, (2001), Intuitionistic fuzzy soft sets. The Journal of Fuzzy Mathematics, 9(3): 677-693.

[11]. Maji P.K, Biswas R and Roy A.R, (2002), An application of soft sets in a decisions making problems, Computers and Mathematics with Applications, 44: 1077- 1083.

[12]. Maji P.K, Biswas R and Roy A.R, (2003), Soft set theory. Computers and Mathematics with Applications, 45: 555-562.

[13]. Molodtsov D, (1999), Soft set Theory-First results, Computers and Mathematics with Applications, 37: 19-31.

[14]. Sezgin A and Atagun A.O, (2011A), On operations of soft sets. Computers and Mathematics with Applications, 60: 1840-1849.

[15]. Sezgin A and Atagun A.O, (2011B), Soft groups and normalistic soft group. Computers and Mathematics with Applications, 62: 685-698.

[16]. V.Vanitha, G.Subbiah and M.NavaneethaKrishnan, On flexible fuzzy subgroups with flexible fuzzy order, international research journal of pure algebra-6(11),2016, 436-442.

[17]. Zadeh L.A,(1965), Fuzzy sets. Information and Control, 8: 338-353. 